Pediat. Res. 2: 271-282 (1968)

Glomerulus myeloid bodies

kidney nephrogenic diabetes

mitochondria insipidus

\title{
Nephrogenic Diabetes Insipidus
}

\author{
A Study of the Fine Structure of the Kidney in a Seven-Month-Old Male
}

\author{
H. Abelson ${ }^{[22]}$ \\ Department of Pediatrics, University of Colorado Medical Center, \\ Denver, Colorado, and the National Cancer Institute, Bethesda, Maryland, USA
}

\begin{abstract}
Extract
This is the first description of the fine structure of the kidney in nephrogenic diabetes insipidus. Striking changes were found throughout the entire kidney. In both proximal and distal tubules, mitochondria contained concentric ringed structures, and many mitochondria had myelin figures associated with their outer membranes as seen in figures 6-13. In figure 9 , the intramitochondrial body is seen to be deforming the outer mitochondrial membrane, and in figure 7 , it is shown to be continuous with this membrane. Cristae were virtually absent in the areas where the concentric ringed structures are found. There was a disruption of the mitochundrial architecture with formation of the ringed bodies which may be the precursors of the myelin figures. In addition to the tubular changes, the glomerular ultrastructure had a predominately fetal configuration which would seem to be unusual in a seven-month-old infant.
\end{abstract}

\section{Speculation}

The alteration in mitochondrial membranes should be correlated with enzymatic studies in this and other tubular disorders. It might then be ascertained whether these mitochondrial changes can be related to the decrease in content of $3^{\prime}-5^{\prime}$ cyclic AMP.

\section{Introduction}

Nephrogenic diabetes insipidus (NDI) is a disorder in which at least a portion of the end organ is defective. There are several reports in which gross and light microscopic changes are briefly mentioned $[8,10,16]$, but there are no published studies of the ultrastructure of the kidney in this disease. DARMADY [2] and others $[5,8]$ have shown that the proximal convoluted tubules are shorter than normal in NDI and in cystinosis. FIASCHI and NACGARATo [7] have reported fine structure changes in diabetes insipidus and other morbid states with polyuria. This paper will present the fine structure changes in the kidney of a seven-month-old male with NDI.
Materials and Methods

Tissue was obtained by percutaneous renal biopsy using a Mehghini needle and local anesthesia. The core was cut into pieces 1 to $2 \mathrm{~mm}$ long and placed in a cold solution of $6.25 \%$ glutaraldehyde and $1 \%$ Acrolein, buffered at $\mathrm{pH} 7.4$ with s-Collidine [1]. After one and one-half hours, the specimen was transferred to a $1 \%$ osmium-tetroxide $\left(\mathrm{OsO}_{4}\right)$ solution buffered with sCollidine for an additional one and one-half hours. The specimen was dehydrated with graded amounts of glycol-methacrylate in water and embedded in Epon epoxy-resin [9]. Sections 1-2 microns thick, cut from the Epon embedded material, were stained with a Mallory's Azur II-methylene blue mixture [12] and 
examined for light microscopy. Ultrathin sections were cut with either a Cambridge Ultramicrotome or an LKB Ultratome using both diamond and glass knives. These sections were placed on Formvar-coated, carbonreinforced, copper grids and double-stained with uranyl-acetate [17] and lead citrate [11]. They were examined with both RCA-EMU 3F and Philips EM 200 electron microscopes.

\section{Case Presentation}

The patient was seven months old when first admitted to the University of Colorado Medical Center with the chief complaint of failure to thrive, complicated by vomiting, constipation, frequent spiking fevers, polyuria, and intermittent weight loss. He was the product of a 42 -week pregnancy complicated only by a 40 -pound maternal weight gain. Labor and delivery were not remarkable. Through the first several months, the infant was noted to have an apparent lack of thirst, constipation, to be very quiet, and to require frequent diaper changes. Despite this, he did well until three months of age when his appetite became poor, he vomited frequently, and began to lose weight. At four months of age, 2-3 day episodes of spiking fever, as high as $39^{\circ}$, began to occur. Because of the persistence of these symptoms, he was first hospitalized in January, 1967 at another hospital. Hypernatremia was present and it was noted that he was unable to concentrate his urine beyond a specific gravity of 1.015. Levels of chlorides in sweat, of calcium, phosphorous, potassium, and urea in serum, and of 17-ketosteroids in urine were normal. No evidence of infection was found. Normal roentgenographic studies included upper and lower gastrointestinal tract, intravenous pyelogram, retrograde pyelogram, bone age at wrists and forearms, and chest. No food intolerances were discovered. The symptoms persisted and he appeared to be getting worse when he was admitted to Colorado General Hospital in April, 1967.

Physical examination showed a small, pale, child who was alert, active, rarely cried, and was in no apparent distress. Vital signs on admission were: Pulse 120 , respirations 28 , temperature $37^{\circ}$, weight $5.57 \mathrm{~kg}$ $(<10 \%)$, height $67 \mathrm{~cm}(50 \%)$, and head circumference $41.5 \mathrm{~cm}(<10 \%)$. A preauricular skin tag was noted on the left. The liver was palpated $2 \mathrm{~cm}$ below the right costal margin and the spleen $1 \mathrm{~cm}$ below the left costal margin. The remainder of the physical examination was within normal limits. During the 2-week hospitalization, he was unable to concentrate his urine beyond a specific gravity of 1.010 . Roentgenograms of the skull, radioisotope brain scan using Technetium$99 \mathrm{~m}$ and electroencephalogram were within normal limits. Levels of sodium and osmolality in serum were consistently above $150 \mathrm{mEq} / 1$ and 300 mosmols respectively. His urine was never hypertonic to plasma and isotonic on only one occasion. An intravenous pyelogram showed both kidneys to be slightly enlarged. With forced water restriction he was unable to concentrate his urine beyond a specific gravity of 1.010 and during a six-hour water restriction, there was a loss of $2.7 \%$ of body weight. There were never complaints of thirst. Two therapeutic trials using a subcutaneous injection of Pitressin were unsuccessful in elevating the urine specific gravity. The infant was given Furosemide [19] $2 \mathrm{mg} / \mathrm{kg}$ orally three days before the renal biopsy was taken. The Furosemide caused a prompt reduction in the level of sodium and osmolality in serum to values within normal range. At the time of discharge in April, 1967, the patient's weight was 5.78 $\mathrm{kg}$. After four months of continuous treatment with the diuretic, there were no demonstrable side effects and the child continued to gain weight. Subsequently, he developed marked polydipsia as well as polyuria.

The diagnosis of NDI has been confirmed in two maternal uncles, aged 22 and 24 years, both of whom had the added complication of hyperuricemia and hydronephrosis. The patient's mother and one of the mother's sisters were also said to be mildly affected.

\section{Results}

\section{Light Microscopy}

Changes seen by light microscopy were limited to the glomeruli. Most glomeruli were hypercellular with epithelial cells forming a rim at the periphery of the glomerular tuft. Their nuclei were enlarged. Outside this rim of epithelial cells was another thin, elongated layer of cells, the lining of Bowman's space. The basement membranes appeared normal.

Some glomeruli possessed a relatively normal configuration, while still other shad distortion of architecture with extensive hyalinization. The tubules showed no demonstrable abnormality. Arterioles and capillaries had a normal appearance (figs. 1A, 1B, 2A, 2B).

\section{Electron Microscopy}

Striking changes were found throughout the length of the nephron, and all sections examined were abnormal. Several different glomerular changes were in evidence (figs. 3 and 4). The epithelial cells were greatly increased in number with large nuclei, scanty amounts of cytoplasm, and few intracytoplasmic organelles. Figure 4 shows a layer of cells, Bowman's capsule, rimming the epithelial cells. Mitochondria, vacuoles, and endoplasmic reticulum were virtually absent. Myelin figures were occasionally seen inside 


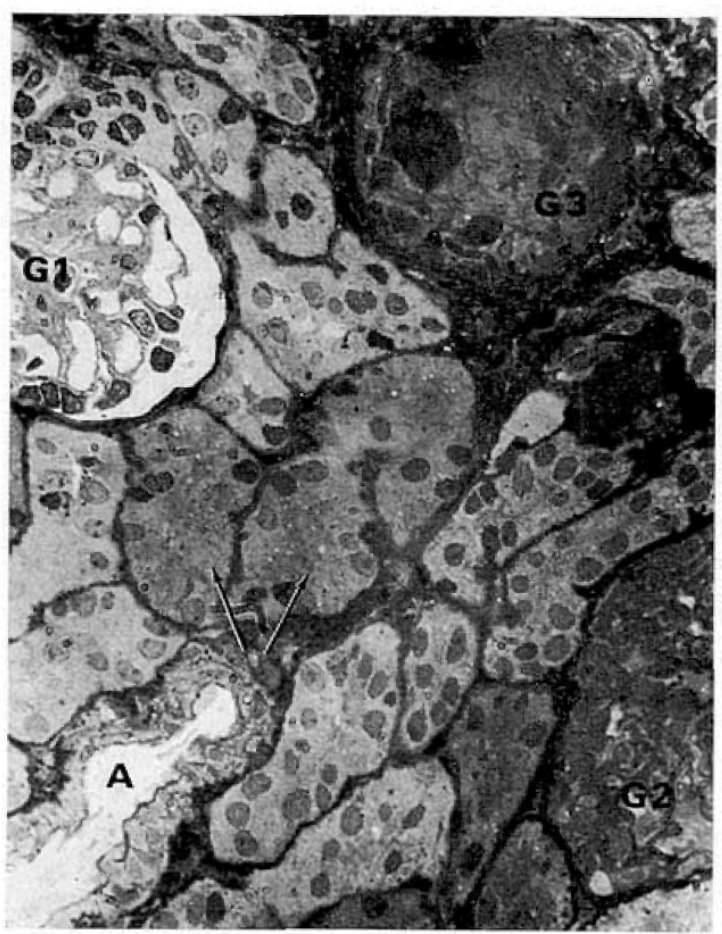

Fig. 1A. Glomeruli are labeled G1, G2 and G3. G1 appears normal. G2 is hypercellular with an immature configuration. G3 has no discernable capillary loops and its architecture is completely distorted. Arrows point to proximal tubules. The other tubules cannot be accurately identified. Magnification $625 \times$.

endothelial and epithelial cells. Most glomeruli had broad, indistinct foot-processes with the coalescence of epithelial cytoplasm into sheets. In places where the foot-processes were well developed they were often filled with small vacuoles (fig. 5). The basement membrane had an altered appearance since the lamina densa was poorly differentiated. Myelin figures were frequently seen in extracellular spaces.

Proximal tubular cells contained abundant protein droplets. Myelin figures were found in large numbers associated with the brush-borders and, therefore, probably in extracellular spaces (fig.6). The myelin figures were also found in close association with the outer mitochondrial membranes. In some places, they appeared to be continuous with the outer mitochondrial membrane (fig. 7). Within mitochondria, there were small concentric ringed inclusions varying from one to four or five in number. The inclusions had as many as five concentric rings, but the majority had only two.

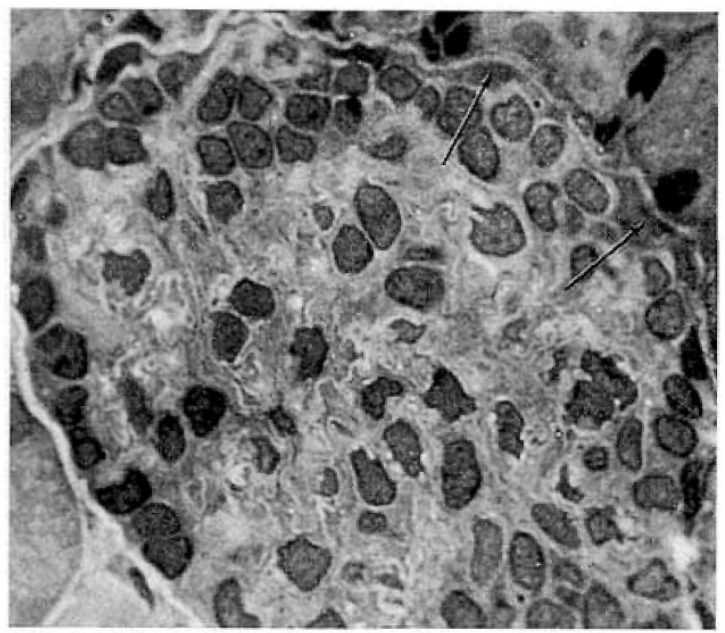

Fig.1B. Immature glomerulus showing increased numbers of epithelial cells with a rim of epithelial cell nuclei at the periphery. Arrows point to the elongated cells of Bowman's capsule. Magnification 1250×.

Abbreviations: A, arteriole; CAP, capillary; BC, Bowman's capsule; BM, basement membrane; $\mathrm{E}$, epithelial cell; En, endothelial cell; G, glomerulus; $\mathrm{L}$, lumen; $\mathrm{M}$, myelin figure; $\mathrm{Mi}$, mitochondria; $\mathrm{N}$, nucleus; $\mathrm{P}$, pinocytotic vessicles; $\mathrm{Pr}$, protein droplet; $\mathrm{PT}$, proximal tubules; V, vacuole.

Their centers were electron lucent. In areas where the inclusions were found, the mitochondrial matrix was prominent and the cristae infrequent (fig.8). In some places, inclusions were seen to be distorting the outer mitochondrial membrane (fig. 9). Vacuolization within the cytoplasm was not excessive. Other intracytoplasmic organelles seemed normal both in number and configuration. No nuclear abnormalities were noted. These same changes, excluding the protein droplets, were present in the loops of Henle, distal tubule, and collecting ducts. There were no other changes peculiar to the distal tubules and collecting ducts (figs. 10, 11, 12 and 13).

\section{Discussion}

The changes in the tissue examined reflect both immaturity and an increased rate in and altered mechanism for lipid breakdown. Light microscopy demonstrated 


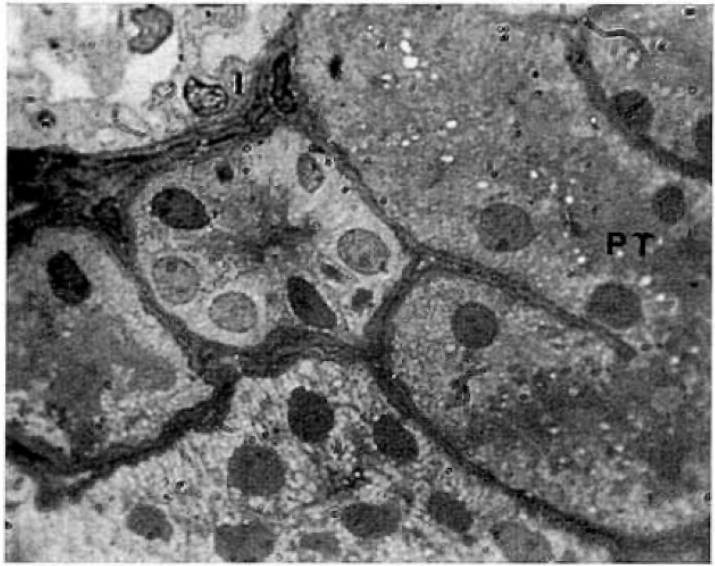

Fig. $2 A$ and B. Normal tubules. Magnification $1250 \times$. For abbreviations see figure 1 .

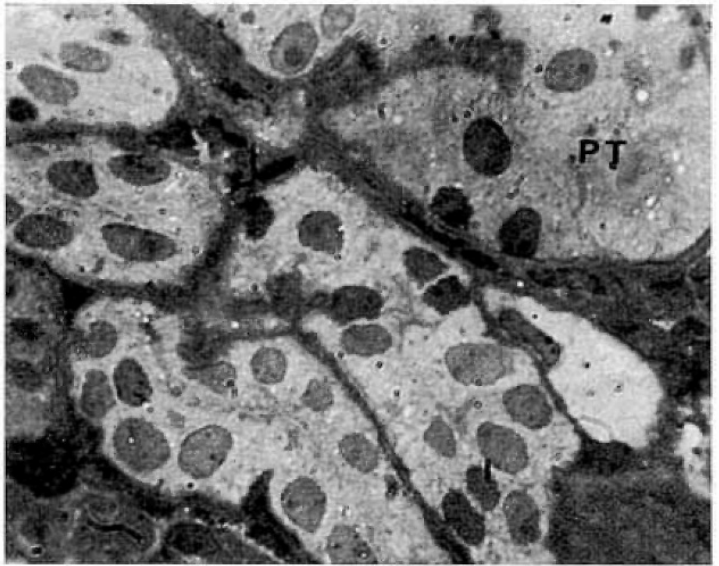

Fig. $2 A$ and B. Normal tubules. Magnification $1250 \times$. For abbreviations see figure 1 .

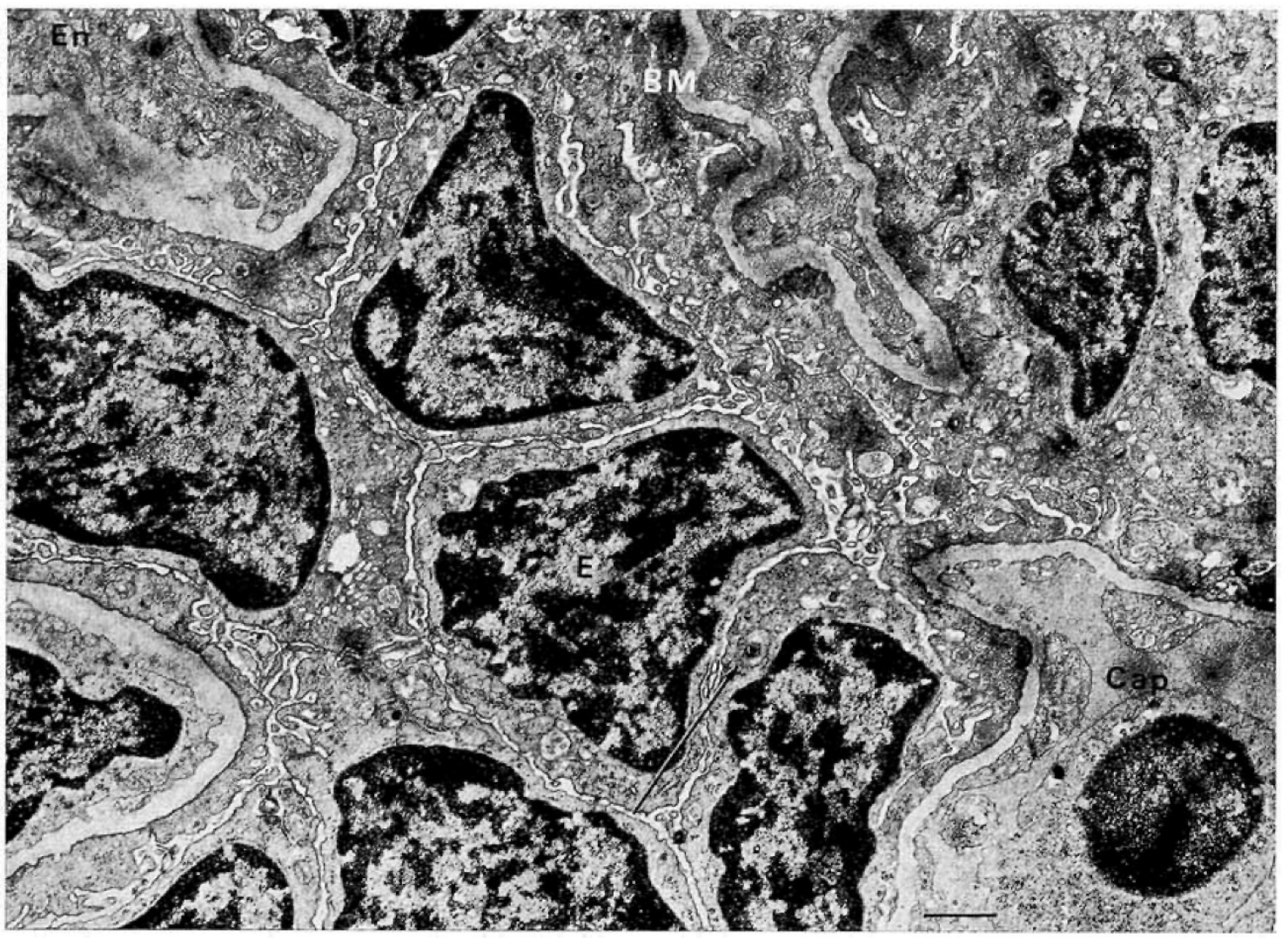

Fig.3. Portion of glomerulus showing large epithelial cells (E) with scanty cytoplasm, few intracytoplasmic organelles, and no foot-processes. The basement membrane (BM) stains indistinctly with no apparent lamina densa. The arrow points to a myelin figure within the cytoplasm of an epithelial cell. For abbreviations see figure 1 . 


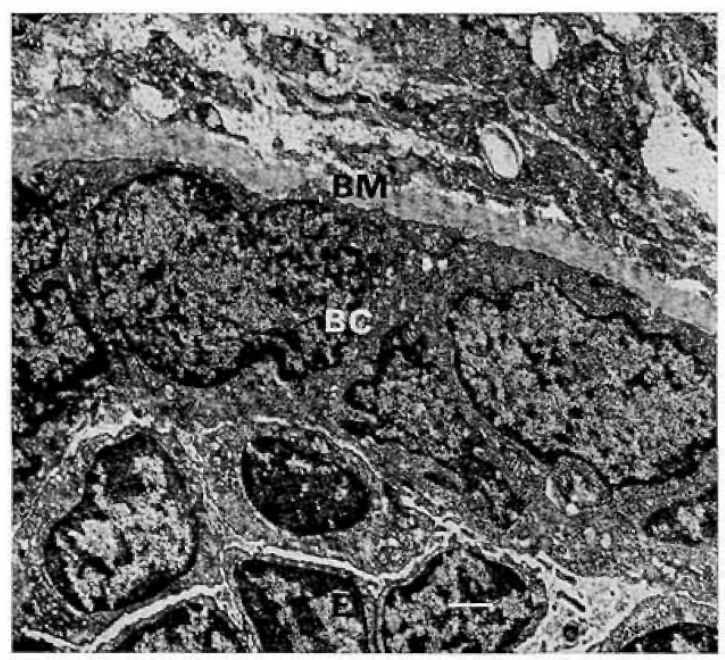

Key to figs. 3-14. In the lower right-hand corner of each electron microscope photograph is a bar equal to 1 micron.

Fig.4. Portion of another glomerulus showing extreme hypercellularity of epithelial components. The cells of Bowman's capsule (BC) have not separated from the parietal epithelial cells. For abbreviations see figure 1.

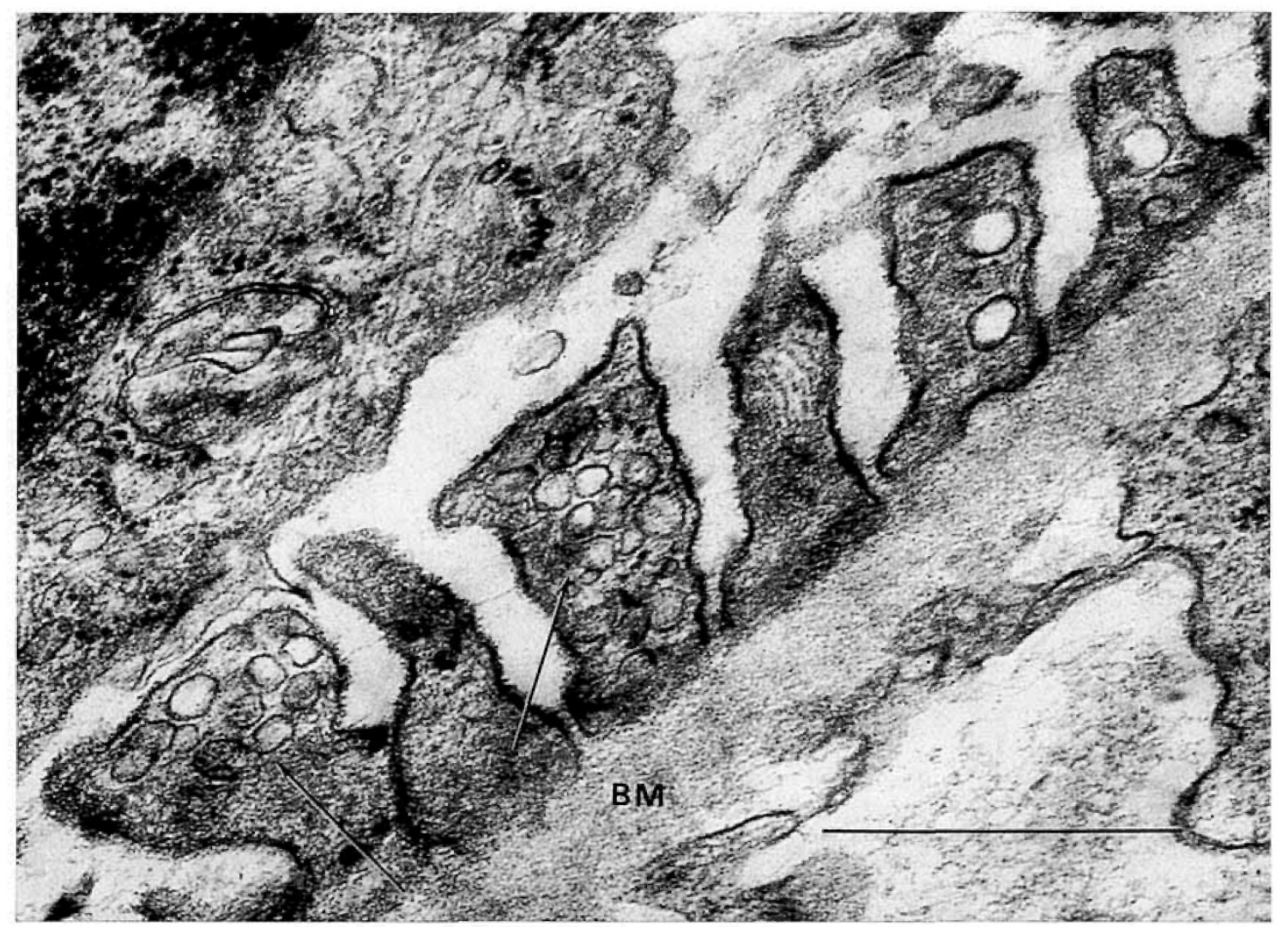

Fig. 5. Foot-processes with numerous vessicles (arrows). The basement membrane is poorly differentiated. For abbreviations see figure 1 . 


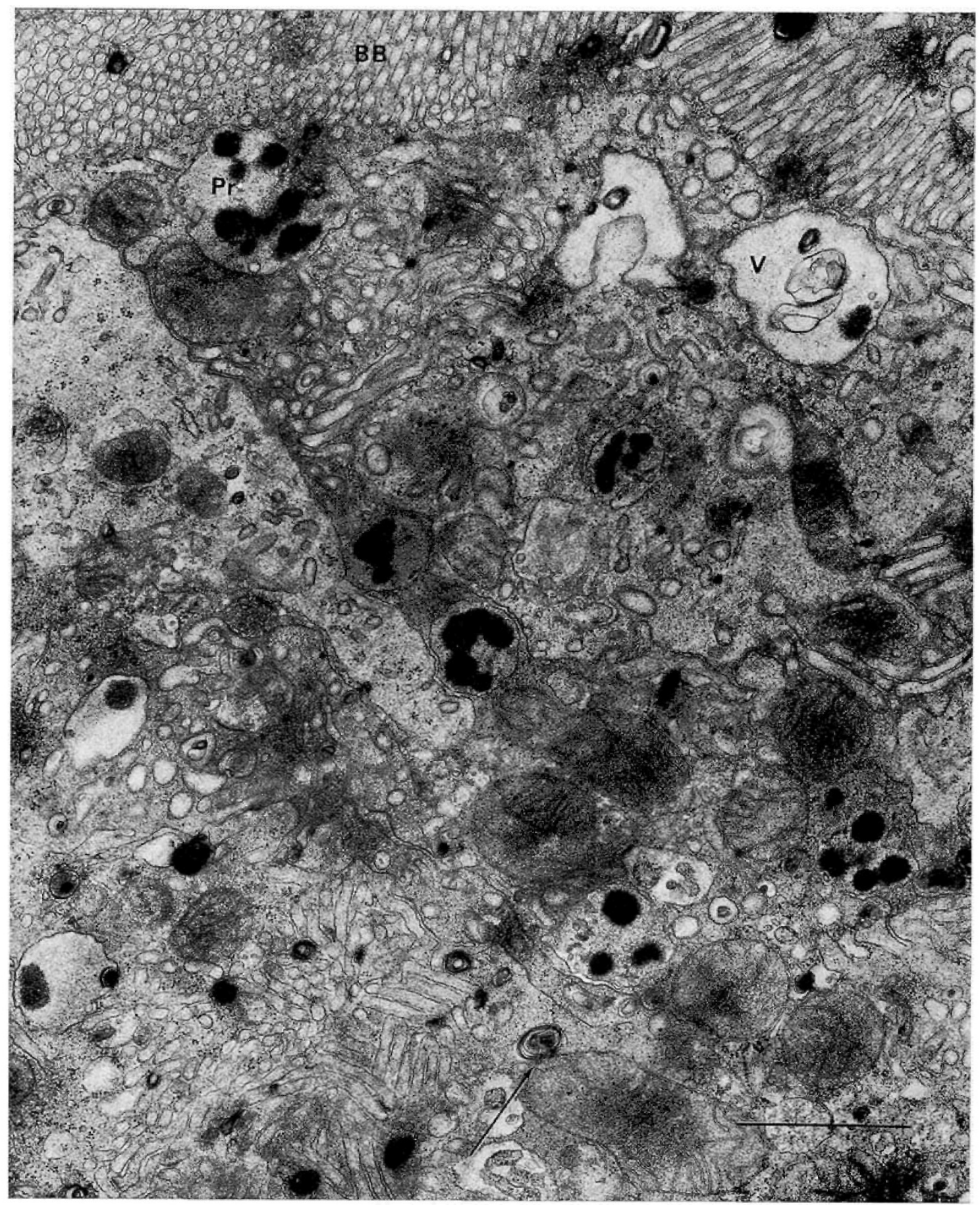

Fig.6. Portion of proximal tubule showing numerous protein droplets $(\mathrm{Pr})$. The arrow points to a myelin figure which seems to be continuous with the outer mitochondrial membrane. For abbreviations see figure 1. 
persistence of an immature configuration of some glomerular epithelial cells. Sclerosis, with deposition of hyaline material, was seen in an occasional glomerular tuft. The latter, neonatal glomerulosclerosis, may affect subcapsular glomeruli toward the end of the first year. Rarely are more than $1 \%$ of the glomeruli involved nor does their presence affect renal function [3]. By electron microscopy, the most obvious abnormality was seen in the glomeruli. The large numbers of hypercellular glomeruli with close-packed epithelial cells having poorly formed foot-processes and scanty cytoplasmic organelles are primarily a reflection of immaturity. The capillary loops, in contradistinction, are not entirely consistent with fetal glomeruli. FETTERMAN and FELDMAN [6] have brieflydescribed the electron microscope picture of two normal biopsy specimens taken from infants 28 days of age who were operated upon for surgical correction of congenital hypertrophic pyloric stenosis and who had no evidence of renal disease. They described an increase in the number of epithelial cells with little cytoplasm and a paucity of cytoplasmic organelles, in comparison with the findings in adult glomeruli. Most striking in our patient was the appearance of the foot-processes which were generally fused into sheets of cytoplasm and covered large areas of the basement membrane without structural differentiation. The more mature the glomerulus, the more numerous and better developed were its footprocesses and the fewer its epithelial components. Vernier and Birah-ANDERson [15] considered that the above changes represent incomplete development within the subcapsular neogenic zone which is the region most readily accessible to biopsy. In their studies, $30 \%$ of the glomeruli from five-month-old fetuses had normal epithelial cell foot-processes; from this, they predicted that the majority of glomeruli in a fullterm infant would have a high degree of differentiation.

In places where the foot-processes were well developed, the majority were filled with vacuoles, although some had a normal appearance (fig. 14). The significance of this finding is unknown.

Numerous analyses of the patient's urine showed no proteinuria or hematuria. Glomerular filtration rate was not measured. No glomerular lesion has been postulated in this disease and this patient showed no evidence of a glomerulopathy.

Because the changes described were found in a patient seven months of age and did not resemble in all respects those of fetal glomeruli, one may speculate that the congenital disease process contributed in some way to the immaturity that was demonstrated.

Myelin figures are often seen in a variety of tissues after fixation with glutaraldehyde followed by osmium. These are commonly extracellular and adjacent to plasma membranes. TRUMP and ERICSSON [13] have

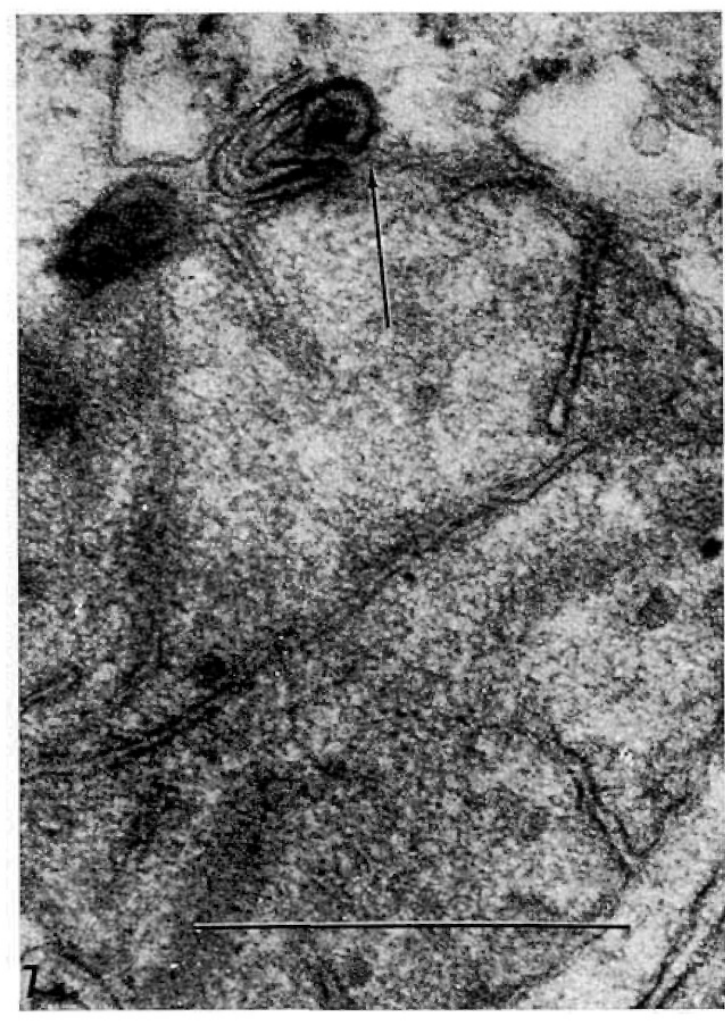

Fig.7. Myelin figure is shown to be continuous with the outer unit membrane of a mitochondrion (arrow). For abbreviations see figure 1 .

suggested that myelin figures form extracellularly as a result of breakdown and solvation of membrane lipid in glutaraldehyde with subsequent fixation of the lipid in $\mathrm{OsO}_{4}$. Some of the myelin figures seen in the present biopsy were extracellular, some could not be accurately located, and many were definitely intracellular. In addition, they were found primarily in association with the outer membrane of mitochondria, and appeared in some places to be continuous with this outer membrane (fig.7). There appeared to be a continuing development of these figures starting with the single and double concentric ringed structures found within the mitochondria. In these areas, there was loss of mitochondrial cristae and obliteration of mitochondrial structure. These intermitochondrial bodies were seen in other locations where they had acquired additional concentric rings and even deformed the outer mitochondrial membrane (fig.9). One possible explanation is the destruction of mitochondrial cristae with progressive formation of the concentric ringed structures which then extruded from the mitochondria. 


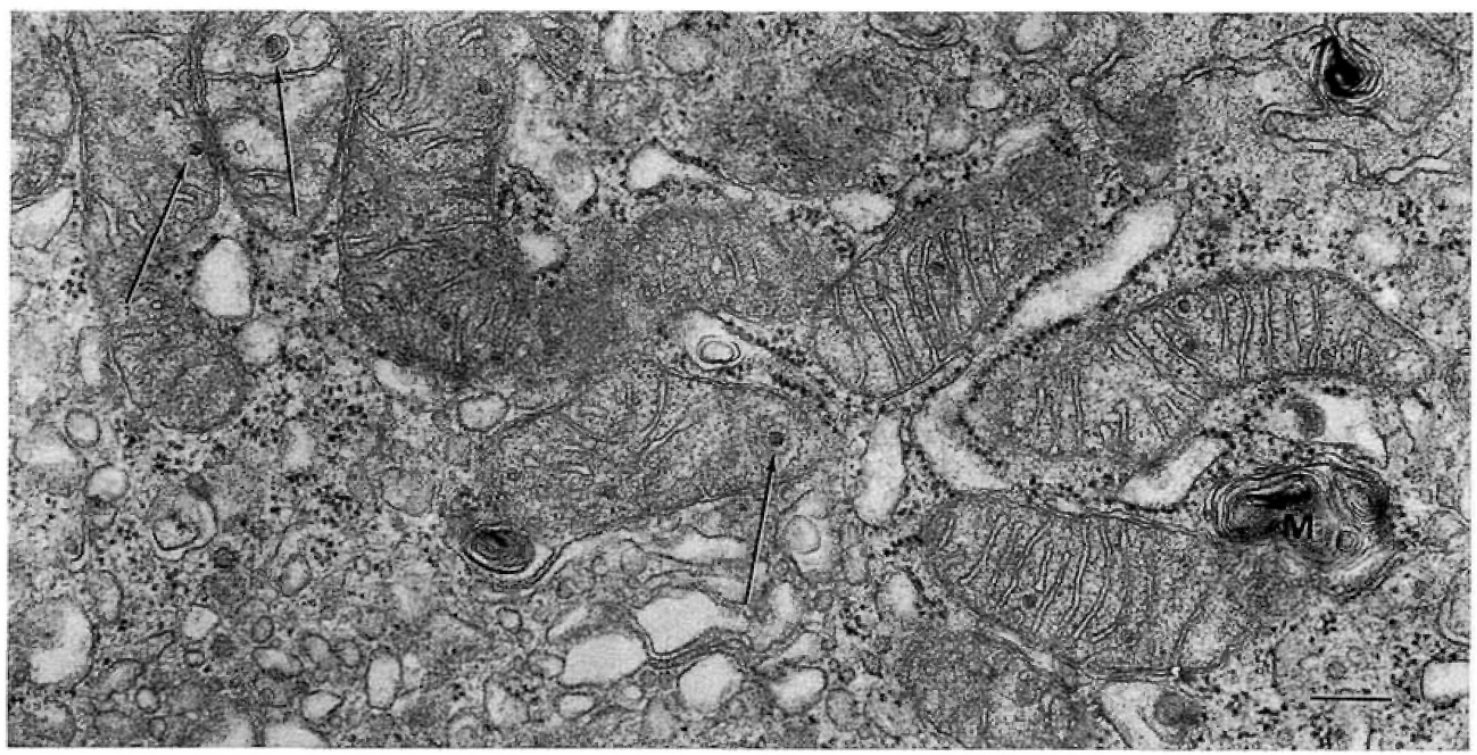

Fig. 8. Numerous concentric ringed structures are seen within mitochondria (arrows) with prominence of the mitochondrial matrix in the areas where they are found. For abbreviations see figure 1. Bar equals. 0.5 micron.

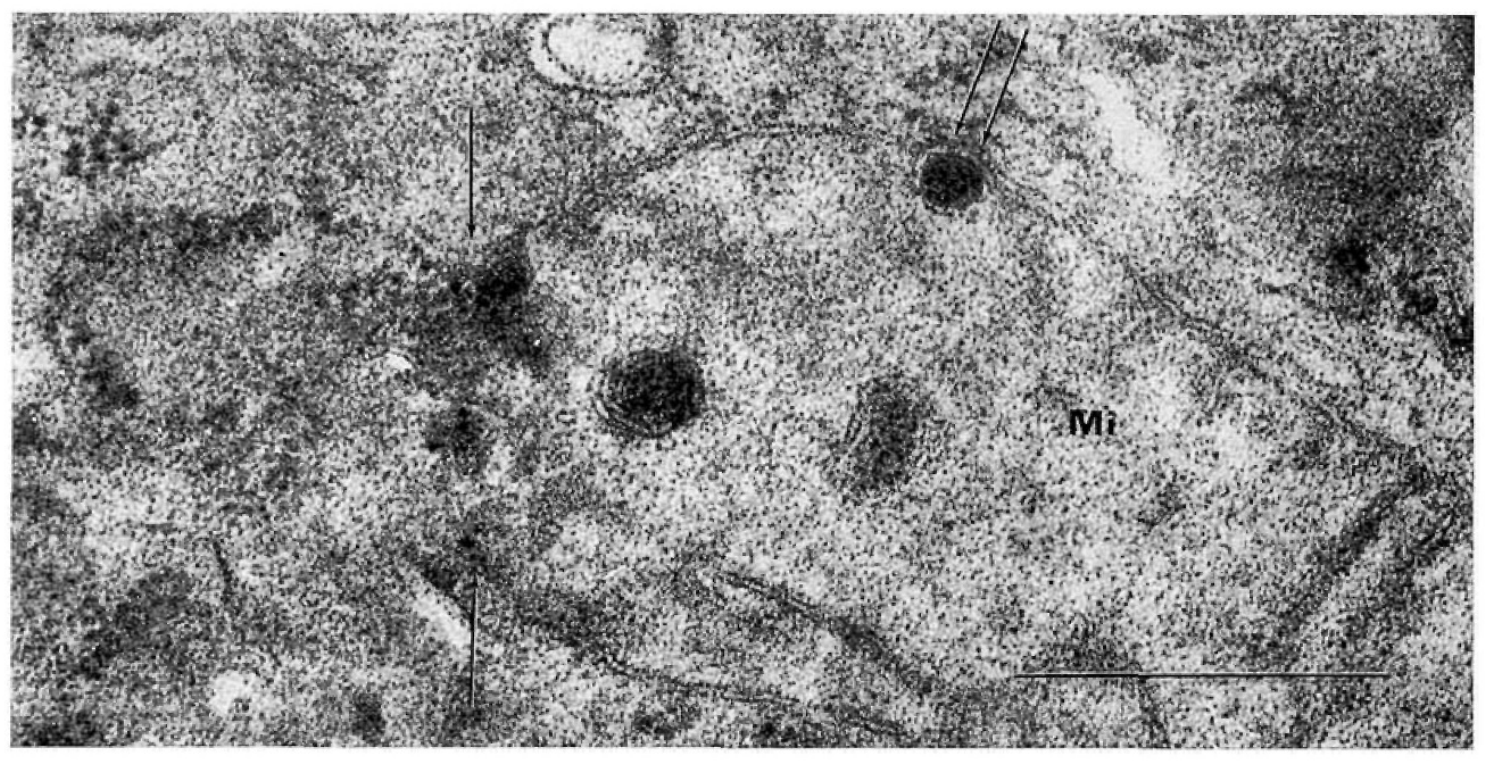

Fig.9. One of the ringed inclusions (double arrow) is seen deforming the outer mitochondrial membrane. Between the opposing arrows, the unit membrane of the mitochondrion has been lost. Few cristae are present within the mitochondrion (Mi). For abbreviations see figure 1 . 


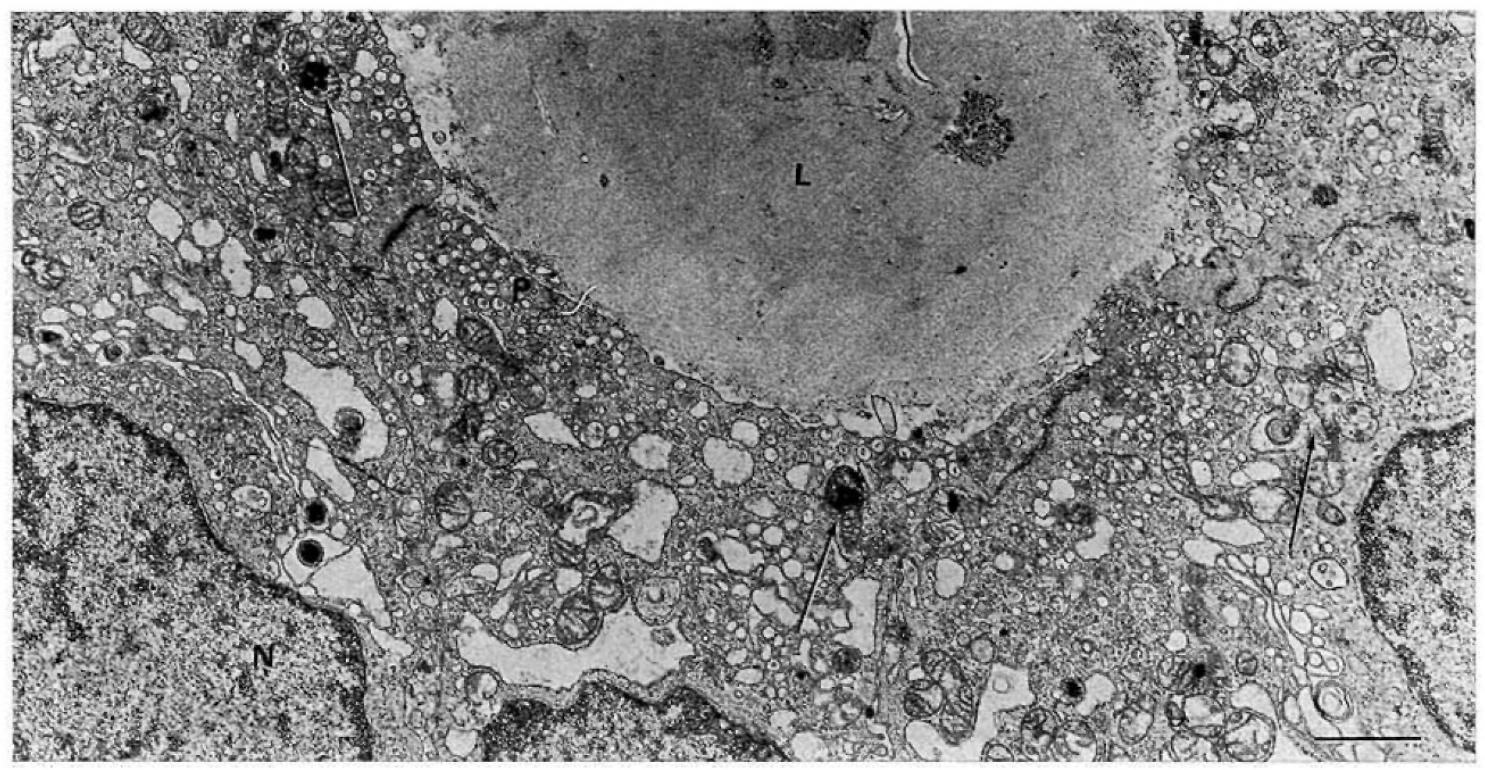

Fig. 10. Thick limb of the Loop of Henle showing numerous pinocytotic vessicles $(\mathrm{P})$ myelin figures, and intracytoplasmic inclusions (arrows). For abbreviations see figure 1.

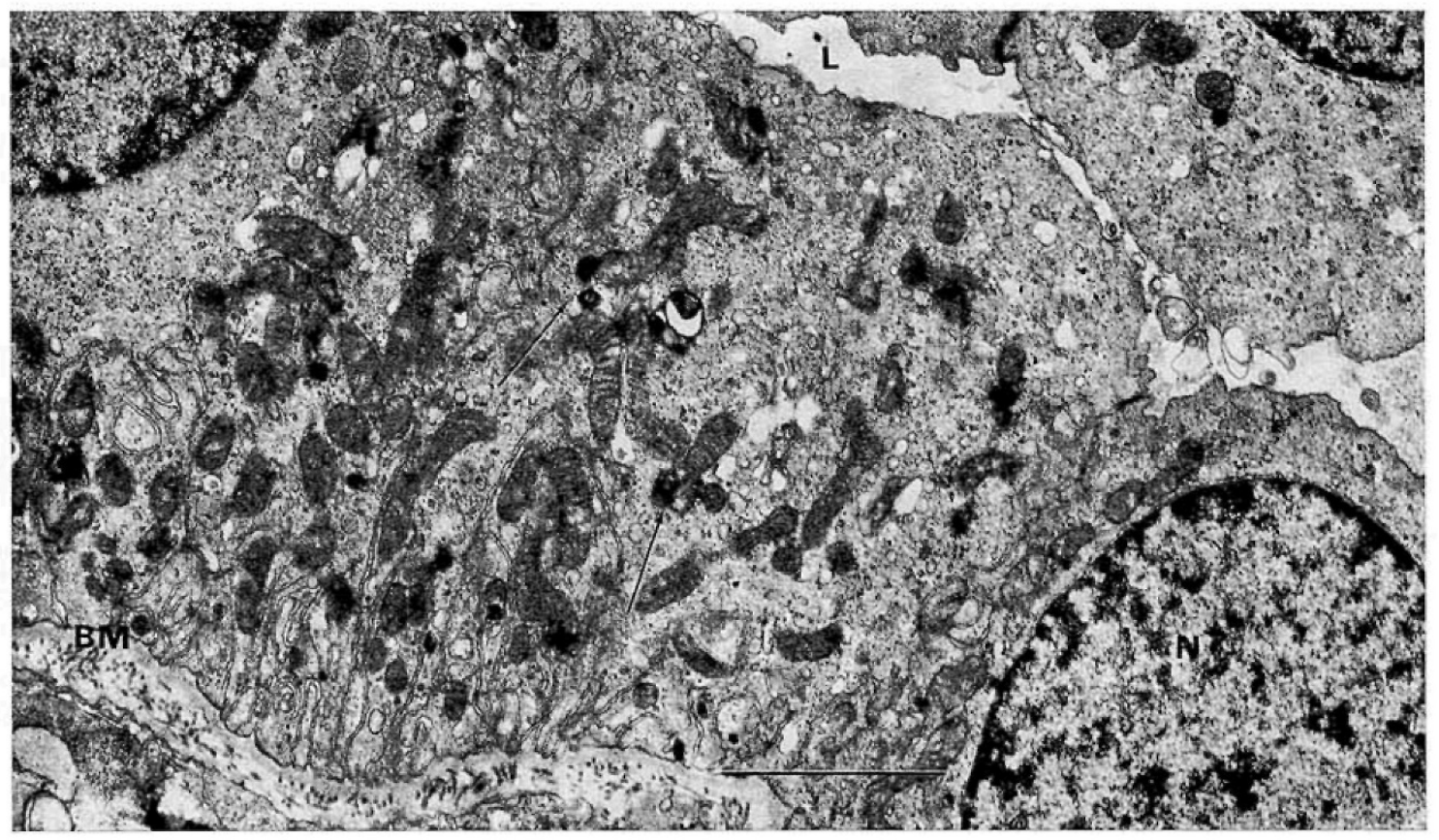

Fig.11. Distal tubule showing infoldings of the plasma basement membrane, myelin figures and ringed inclusions (arrows). For abbreviations see figure 1. 


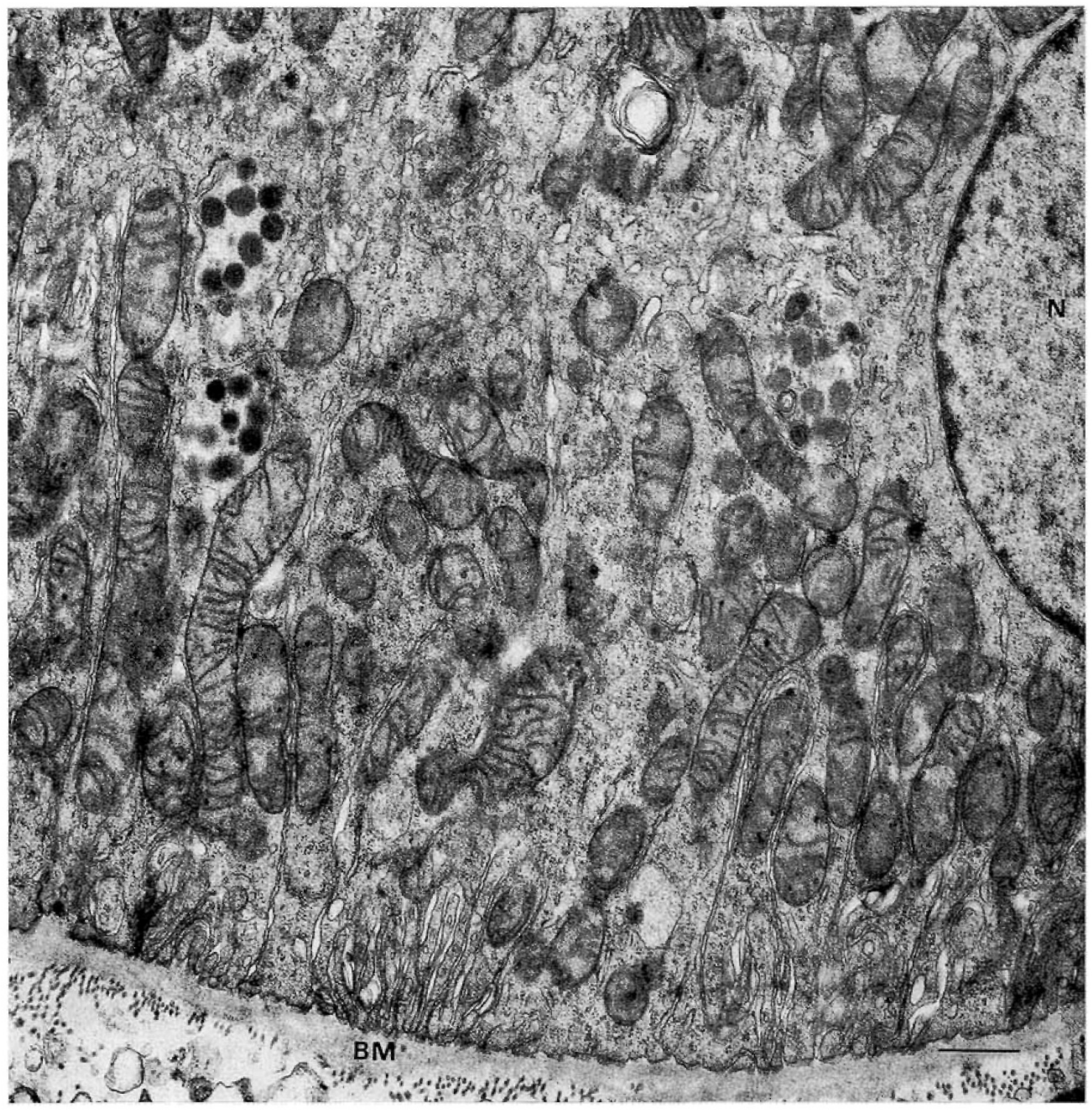

ERICSSON and BIBERFELd [4] have taken whole liver lobes from rats and fixed them in glutaraldehyde. They described a zone of intermediate fixation in which mitochondria were enlarged with irregular pallor of the matrix, discontinuities of the outer membranes and the presence of internal myelin figures. In these same areas, endoplasmic reticulum retained a normal shape and distribution. The preparation and handling of this tissue were, however, so different from that used for a small core renal biopsy that the situations are not analogous. Conjecture about glutaraldehyde artifacts could be eliminated by demonstrating enzymatic ac- tivity in association with these myelin figures, for it has been suggested that they are part of the continuum of lysosome formation [18]. The $\mathrm{OsO}_{4}$ fixation and Epon embedding precluded the possibility of acid phosphatase localization on this particular specimen.

In our laboratory, myelin figures are not commonly seen in human renal biopsies or in mouse kidney preparations. When myelin figures are encountered in these tissues, they are unrelated to outer mitochondrial membranes. Intramitochondrial bodies described here have never been observed.

One could surmise that alteration in mitochondrial 


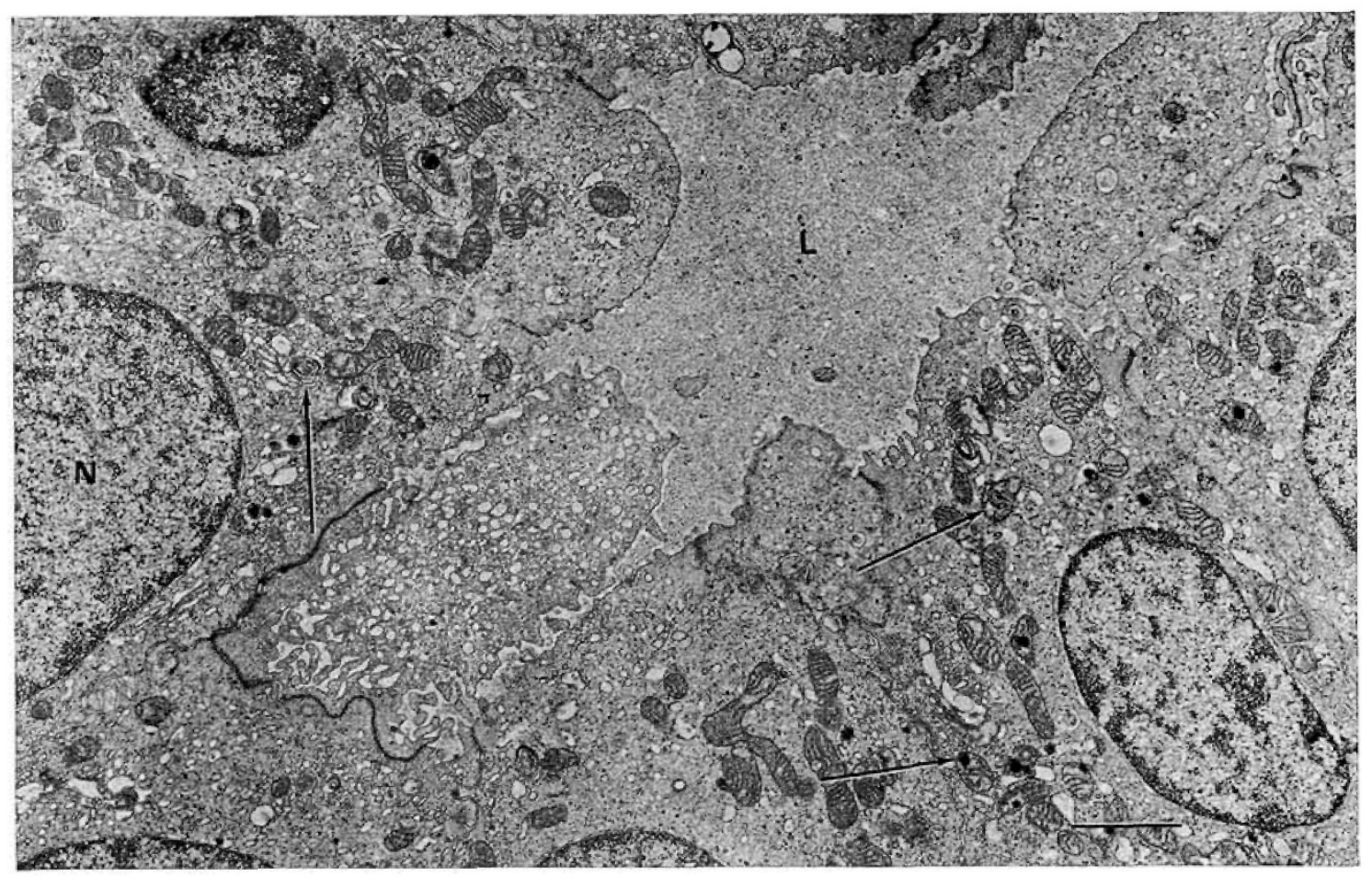

$\Delta$

Fig. 13. Collecting duct with myelin figures and ringed inclusions indicated by arrows. For abbreviations see figure 1 .

Fig.12. Another portion of distal tubule showing changes similar to those seen in figure 11. For abbreviations see figure 1 .

Fig. 14. Normal appearing foot-processes. The basement membrane shows some differentiation into a lamina densa portion (arrow) For abbreviations see figure 1 .

membranes throughout the kidney is either a cause of or response to alteration in the properties of the membrane. To conclude that unresponsiveness to Pitressin is somehow related to these changes in membrane characteristics is unjustified on the basis of the evidence available at present.

Studies on mice conducted in this laboratory confirm that Furosemide in dosages greater than those used in this patient has no demonstrable effect on renal ultrastructure.

Further investigations into the structural aspects of this disease are needed. When these studies are under-

19 Pediat. Res., Vol. 2, No. 4 (1968)

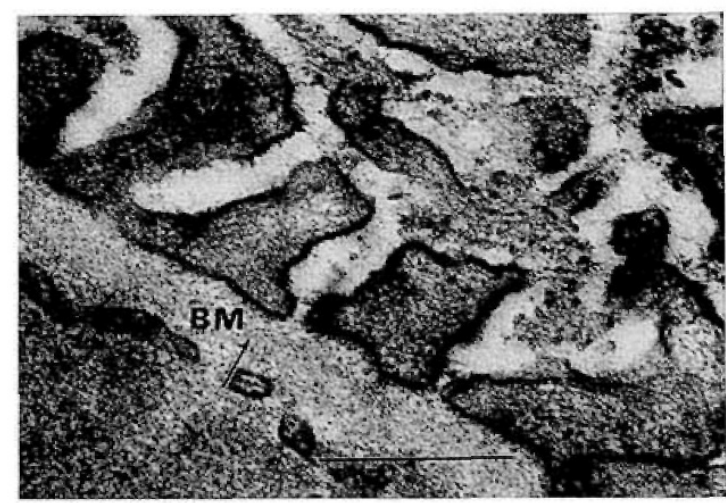

taken, an attempt should be made to investigate the activity of lysosomal and other intracellular enzymes.

\section{Summary}

Light and electron microscopic studies in a single kidney biopsy specimen obtained from a seven-monthold infant with nephrogenic diabetes insipidus were performed. The observed changes in ultrastructure suggested immaturity of the glomeruli and an abnormality in mitochondrial membrane lipids. 


\section{References and Notes}

1. Bennett, H.S. and Luft, J.H.: s-Collidine as a basis for buffering fixatives. J. biophys. biochem. Cytol. 6: 113 (1959).

2. Darmady, E. M.; Offer, J.; Prince, J. and StrraNACK, F.: The proximal convoluted tubule in the renal handling of water. Lancet $i i: 1254$ (1964).

3. Emery, J.L. and Macidonald, M.S.: Involuting and scarred glomeruli in the kidney of infants. Amer.J.Path. 36: 713 (1960).

4. Ericsson, J.L.E. and Biberfeld, P.: Studies on aldehyde fixation: Fixation rates and their relation to fine structure and some histochemical reactions in liver. Lab. Invest. 17: 281 (1967).

5. Fetterman, G.H. and Fabrizio, N. S.: The application of renal microdissection to the study of kidney disease in infancy and childhood. Clin. Ped. 5: 626 (1966).

6. Ferterman, G.H. and Feldman, J. D.: Congenital abnormalities of renal tubules in a case of 'infantile nephrosis'. Amer. J. Dis. Child. 100: 319 (1960).

7. Fraschi, E. and NacGarato, R.: Ultrastructural changes of the human renal tubule in some polyuric conditions. Arch.ital. Anat. Istol.pat. 37: 253 (1963).

8. KiRMAN, B. H. ; Black, J.A.; Wilkinson, R.H. and Evans, P.R.: Familial pitressin-resistant diabetes insipidus with mental defect. Arch. Dis. Childh. 31: $59 \cdot(1956)$.

9. LUFT, J.H.: Improvements in epoxy resin embedding methods. J.biophys. biochem. Gytol. 9: 409 (1961).

10. MACDONALD, W.B.: Congenital pitressin resistant diabetes insipidus of renal origin. Pediatrics 15: 298 (1955).

11. Reynolds, E.S.: The use of lead citrate at high $\mathrm{pH}$ as an electron-opaque stain in electron microscopy. J. Cell Biol. 17: 208 (1963).

12. Richardson, K. G.; Jaretr, L. and Finke, E.: Embedding in epoxy resins for ultrathin sectioning in electron microscopy. Stain Tech. 35: 313 (1960).

13. TRUMP, B.F. and ERICsson; J.L.E.: The effect of the fixative solution on the ultrastructure of cells and tissues. Lab. Invest. 14: 1245 (1965).

14. Vernier, R. L.: Personal communication.

15. Vernier, R. L. and Birch-Anderson, A.: Studies of the human fetal kidney. I. Development of the glomerulus. J.Pediat. 60: 754 (1962).

16. WARING, A.J.; KAJDI, L. and TAPPAN, V.: A congenital defect of water metabolism. Amer.J. Dis. Child. 69: 323 (1945).

17. Watson, M.L.: Staining of tissue sections for electron microscopy with heavy metals. J. biophys. biochem. Cytol. 4: 475 (1958).

18. Weissmann, G.: Lysosomes. New Engl.J.Med. 273: 1084 (1965).

19. Lasix, Hoechst Pharmaceuticals, Inc.

20. The author would like to thank Dr. Albert VATTER for encouragement and use of his electron microscope and Mr. Howard Mitchell for technical assistance.

21. Supported in part by USPHS Research Grant FR-00069.

22. Requests for reprints should be addressed to: Herbert Abelson, M.D., National Cancer Institute, Viral Biology Branch, Bethesda, Md. 20014 (USA). 